\title{
A shift to avoid Covid-19 risk and safeguard health governance
}

Francesco Ferrara ${ }^{1}$ and Antonio Vitiello ${ }^{1}$

${ }^{1}$ Azienda Unità Sanitaria Locale Umbria 1

May 7, 2020

\begin{abstract}
Immunosuppressive therapies, such as multiple sclerosis, are a risk for people with this condition because they can expose them to a greater risk of Sars-CoV-2 infection. For these reasons, recommendations from agencies, patient associations and scientific societies follow one another quickly so that therapy is guaranteed with good efficacy and without risk, choosing from the many drugs available in multiple formulations.
\end{abstract}

\section{Hosted file}

lettera sm e politica sanitaria.odt available at https://authorea.com/users/315673/articles/ 449108-a-shift-to-avoid-covid-19-risk-and-safeguard-health-governance 